\title{
Fast Spectrophotometric Determination of Iodine Value in Biodiesel and Vegetable Oils
}

\author{
Samara Soares ${ }^{a}$ and Fábio R. P. Rocha ${ }^{*, a}$ \\ ${ }^{a}$ Centro de Energia Nuclear na Agricultura, Universidade de São Paulo, \\ Av. Centenário 303, 13416-000 Piracicaba-SP, Brazil
}

\begin{abstract}
Iodine value is an important quality parameter for evaluation of the oxidative stability of biodiesel and vegetable oils, but the official methods are time-consuming and demand large amounts of reagents and solvents. The present work describes a novel procedure for determination of iodine value based on the discoloration of a triiodide aqueous solution due to halogenation of the unsaturated compounds in the samples. Iodine is extracted to the organic phase and consumed proportionally to the amount of unsaturated compounds in the samples. Thus, the remaining fraction of $\mathrm{I}_{3}^{-}$quantified by spectrophotometry in the aqueous phase is inversely proportional to the concentration of unsaturated compounds. For biodiesel samples, responses were linear from 10 to $106 \mathrm{~g} \mathrm{I}_{2}$ per $100 \mathrm{~g}$, with coefficient of variation and limit of detection estimated at $5.0 \%(\mathrm{n}=8)$ and $2.5 \mathrm{~g} \mathrm{I}_{2}$ per $100 \mathrm{~g}$, respectively. The corresponding values for vegetable oils were 20 to $140 \mathrm{~g} \mathrm{I}_{2}$ per $100 \mathrm{~g}, 3.0 \%(\mathrm{n}=10)$, and $7 \mathrm{~g} \mathrm{I}_{2}$ per $100 \mathrm{~g}$, respectively. The procedure consumed only $1.2 \mathrm{~mL}$ of sample, $365 \mu \mathrm{g}$ of $\mathrm{I}_{2}$, and $42 \mathrm{mg}$ of KI with ca. $2.4 \mathrm{~mL}$ of waste generated per determination. The results agreed with those obtained by the official methods at the $95 \%$ confidence level.
\end{abstract}

Keywords: unsaturation, oxidative stability, biofuel, green analytical chemistry

\section{Introduction}

Vegetable oils are extracted from seeds, such as soy, cotton, corn, and sunflower. They are characterized by high concentrations of triglycerides and lower amounts of mono and diglycerides, free fatty acids, tocopherols, proteins, sterols, and vitamins. ${ }^{1}$ Triglycerides with a high number of unsaturations predominate in most of the vegetable oils (e.g. soy, cotton, corn, and sunflower oils), which makes them more susceptible to oxidation. ${ }^{2}$ Some refined oils, such as those extracted from sunflower, canola, and soybean are essentially intended for food preparation. On the other hand, oils are also widely demanded for biodiesel production (e.g. soybean and cotton oils), which alternatively can be produced from animal fats. Biodiesel is obtained by transesterification of these raw materials with a short chain alcohol (methanol or ethanol), in the presence of a catalyst, which is typically a strong base. ${ }^{3,4}$

Quality control is essential to ensure the integrity of vegetable oils and biodiesel that will be marketed. Both the raw material and the industrial process can introduce contaminants and yield by-products, whereas transport and storage can cause product degradation, which make

*e-mail: frprocha@cena.usp.br essential the establishment of quality standards. ${ }^{5}$ Among the parameters to be monitored in vegetable oils are acidity, iodine, and saponification indexes, and physical constants, such as melting point and refractive index. ${ }^{6}$ In relation to biodiesel, iodine and acidity indexes, free and total glycerol, as well as ester content need to be monitored. ${ }^{7}$

Iodine value is proportional to the degree of unsaturation of the product and indicates its oxidative stability. ${ }^{8}$ The official method for biodiesel and vegetable oils (EN 14111) ${ }^{9}$ is based on titration of the excess of a halogen reagent with a sodium thiosulfate solution..$^{9-11}$ It is time-consuming, requires a large reagent amount (e.g. $25 \mathrm{~mL}$ of Wijs reagent) and consequently generates a significant waste volume. ${ }^{9}$ Currently, with the growth in the production of vegetable oils and biodiesel, faster and greener analytical procedures are needed for quality control. In this sense, a flow-based procedure ${ }^{12}$ and a quantitative spot test ${ }^{13}$ were proposed for determination of iodine value in biodiesel and alternative volumetric procedures were developed for vegetable oil samples. ${ }^{11}$ Applicability of these procedures for both vegetable oils and biodiesel was not evaluated and, except for the spot test, the procedures are not suitable for in situ analysis, i.e., directly at the production plants. In this context, the present work proposes the development of a greener 
procedure for fast determination of iodine value in both vegetable oils and biodiesel.

\section{Experimental}

\section{Equipment and accessories}

A vortex (Nova instruments) with capacity for up to nine $15 \mathrm{~mL}$ Falcon tubes and agitation maximum of $1800 \mathrm{rpm}$ and a mixing table (Tecnal, TE-140) were used in the procedures for biodiesel and vegetable oils, respectively. A centrifuge (Quimis, model 6222T108) was used for phase separation and the aqueous phases were removed with $5 \mathrm{~mL}$ hypodermic syringes connected to Tygon ${ }^{\circledR}$ tubes (2.8 mm i.d.). A UV-visible spectrophotometer (Femto, model 700Plus) equipped with a $1 \mathrm{~cm}$ quartz cuvette was used for the spectrophotometric measurements.

\section{Reagents and solutions}

Solutions were prepared using analytical grade chemicals (Merck) and ultrapure water (resistivity > $18.2 \mathrm{M} \Omega \mathrm{cm}$ ). Biodiesel and degummed soybean oils were obtained directly from biodiesel production plants and refined oils were purchased at the local market. All biodiesel samples agreed the quality standards established by the Brazilian regulatory agency (ANP). Reference samples of biodiesel and vegetable oil (i.e., samples with iodine value previously determined by the reference procedures) ${ }^{11,14}$ were used for optimization of the procedure and for preparation of the reference solutions by dilutions in $n$-hexane (fractions 0 to $100 \% \mathrm{v} / \mathrm{v})$. Accuracy was assessed with biodiesel samples (from animal fat, soybean and cotton oils), refined oils produced from canola, soybean, and sunflower seeds and soybean degummed oils. Before analysis, biodiesel and vegetable oil samples were diluted 1:1 (v/v) and 1:2(v/v) in hexane, respectively.

A $1.2 \mathrm{mmol} \mathrm{L}^{-1}$ triiodide reference solution was prepared by dissolving $30 \mathrm{mg}$ of $\mathrm{I}_{2}$ in $15 \mathrm{~mL}$ of ethanol, followed by addition of KI to a final concentration of $0.210 \mathrm{~mol} \mathrm{~L}^{-1}$ and marking the volume up to $100 \mathrm{~mL}$ in a volumetric flask. Hexane replaced the samples for measurement of the reference signals, i.e., those obtained without consumption of iodine for halogenation of the unsaturated compounds.

\section{Procedure}

The analytical procedure was carried out in $15 \mathrm{~mL}$ polypropylene (Falcon) tubes based on the single vial principle. First, $1.0 \mathrm{~mL}$ of biodiesel or $1.2 \mathrm{~mL}$ of vegetable oil samples and $1.2 \mathrm{~mL}$ of the $\mathrm{I}_{3}^{-}$solution were added to the tube, which was shaken for 5 min to extract $I_{2}$ to the organic phase aiming at reaction with the unsaturated compounds. Subsequently, the mixture was centrifuged for 2 min to separate the phases before removal of the aqueous phase with a syringe. The remaining $\mathrm{I}_{3}{ }^{-}$was measured by spectrophotometry at $450 \mathrm{~nm}$. The analytical signal was obtained by the difference between the signals obtained in the absence (replaced by hexane) and presence of the sample. The procedure was optimized by the univariate method and all measurements were taken in triplicate.

\section{Results and Discussion}

\section{General aspects}

The determination of iodine value was based on the discoloration of an aqueous triiodide solution added to biodiesel or vegetable oil, due to the halogenation of the unsaturated compounds in the sample (equation 1). As these unsaturated compounds show very low solubility in water, the reaction occurs in the organic phase and it is favored because $\mathrm{I}_{2}$ is soluble in biodiesel and vegetable oils. In this way the proposed procedure involved three steps: (i) extraction of $\mathrm{I}_{2}$ to the organic phase, (ii) halogenation reaction, and (iii) measurement of the remaining $\mathrm{I}_{2}$ in the aqueous phase.

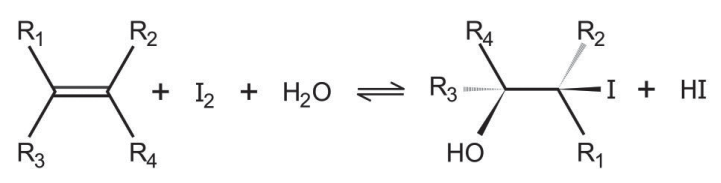

The indirect determination of iodine value by measurements in the aqueous (instead of organic) phase avoids the drawbacks caused by the color of the samples, which absorb radiation at the same wavelength of the reagent. This simplifies the analytical procedure by avoiding the need for a correction step for the background absorption by the sample ${ }^{15}$ or a derivatization step, ${ }^{13}$ thus making the procedure more attractive for routine analysis.

Because of the lack of a commercially available species to mimic the unsaturated compounds found in biodiesel and vegetable oils, calibration was carried out with reference samples (biodiesel and vegetable oil containing 106 and $144 \mathrm{~g} \mathrm{I}_{2}$ per $100 \mathrm{~g}$, respectively), whose iodine values were determined by the reference procedures. ${ }^{11,14}$ This strategy also yielded reliable results in previous works. ${ }^{12,13}$

Discoloration of the $\mathrm{I}_{3}^{-}$solution results from both the consumption of $\mathrm{I}_{2}$ in the halogenation of the unsaturated compounds and its solubility in the organic sample. In this way, a solvent for sample dilution should ideally present the same ability to dissolve $\mathrm{I}_{2}$ than biodiesel and vegetable oils. 
However, solubility of $\mathrm{I}_{2}$ in the samples cannot be evaluated independently because of its intrinsic consumption in the halogenation of unsaturated compounds. Alternatively, it was experimentally evaluated that dilution of the reference samples in $n$-hexane yielded a linear response between absorbance in the aqueous phase and the iodine value in the samples. This indicates that the solubility of $\mathrm{I}_{2}$ is not significantly altered by the addition of this diluent and thus the ideal condition previously mentioned was achieved. Moreover, $n$-hexane is relatively cheaper and often used for the dilution of biodiesel samples in analytical procedures. ${ }^{13-16}$

\section{Optimization}

\section{lodine value in biodiesel samples}

In relation to $I_{2}$ concentration, both the analytical and reference signals increased linearly in the evaluated interval (Figure 1A). This indicates that the organic phase (biodiesel or $n$-hexane in the curves $\mathrm{b}$ and a, respectively) is not saturated with $\mathrm{I}_{2}$. The curve referent to biodiesel shows a lower slope because of the reagent consumption in the halogenation reaction and thus the net analytical signal increases with the $\mathrm{I}_{2}$ concentration. An iodine concentration of $1.2 \mathrm{mmol} \mathrm{L}^{-1}$ was chosen to avoid absorbance values higher than 1.0 and thus the increase of the uncertainty in the spectrophotometric measurement.

Iodide is essential for dissolution of $\mathrm{I}_{2}$ in water (as triiodide) as well as for extraction of the remaining $\mathrm{I}_{2}$ back to the aqueous phase. However, KI concentration had a low effect on the signal below the concentration of $160 \mathrm{mmol} \mathrm{L}^{-1}$ (Figure 1B), with signals variations lower than $2 \%$. Poor linearity was observed when a solution in this concentration was used as reagent $(\mathrm{r}=0.961)$. This drawback was solved by using $210 \mathrm{mmol} \mathrm{L}^{-1} \mathrm{KI}(\mathrm{r}=0.998)$, which favored the extraction of the remaining $\mathrm{I}_{2}$ from the organic phase. For higher iodide concentrations, the net signal tends to diminish because the partition of $\mathrm{I}_{2}$ to the organic phase is hindered.

The time for the halogenation reaction was evaluated aiming to achieve the chemical equilibrium condition (Figure 1C), which was reached from 2 min of reaction. This was observed for a biodiesel sample with (Figure 1C, curve c) and without (Figure 1C, curve b) dilution in $n$-hexane. However, to assure the attainment of the steady state even with lower ambient temperatures, a $5 \mathrm{~min}$ reaction time was selected for further measurements.

\section{lodine value in vegetable oils}

Because of the significant amounts of free fatty acids in the vegetable oils, emulsions were formed
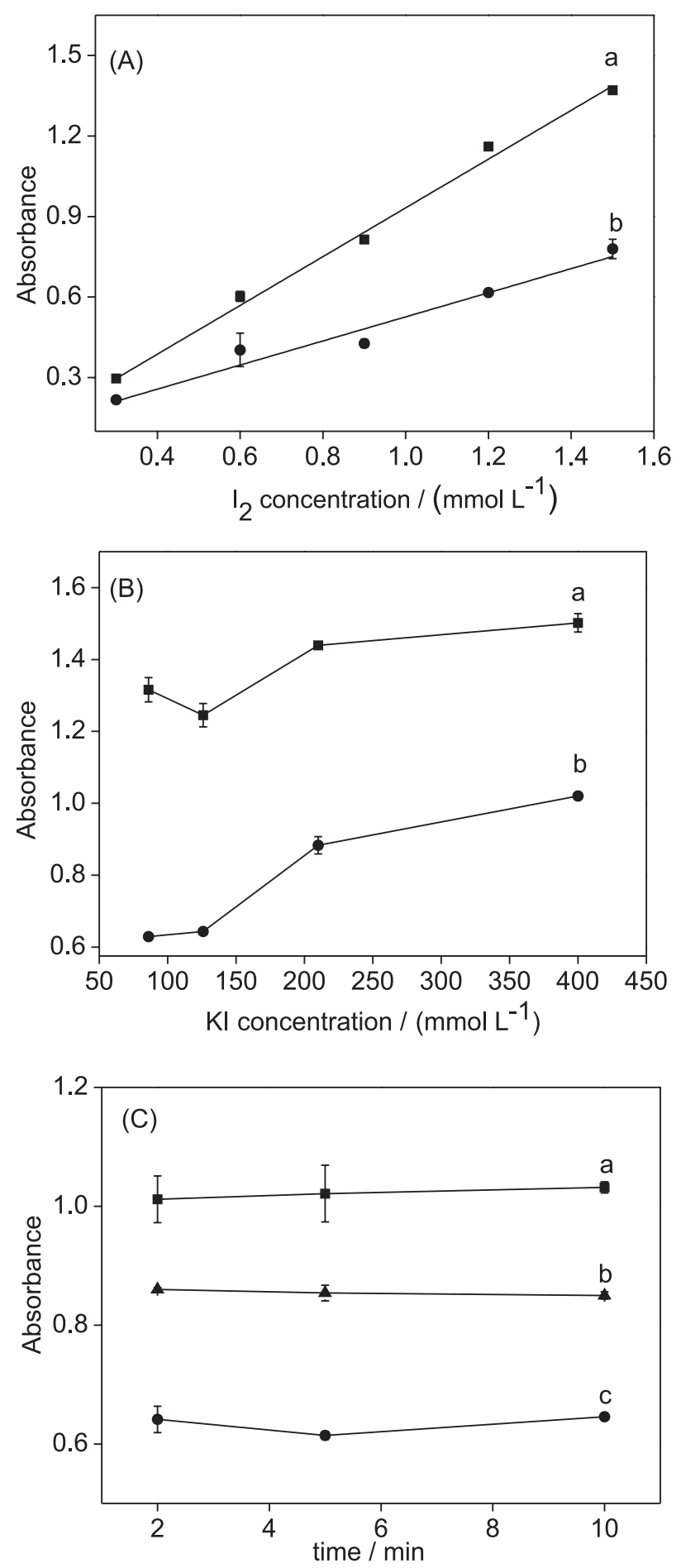

Figure 1. Effect of the reagent concentration (A, B) and reaction time (C) on the reference (a) and analytical (b and c refers to the sample without and with 1:1 (v/v) dilution in hexane) signals. Results refer to mean values of triplicate measurements taken with $1.2 \mathrm{~mL}$ reagent and $1 \mathrm{~mL}$ sample and reaction time of 5 min (except in Figure 1C).

when samples were processed under the conditions optimized for biodiesel. ${ }^{17}$ This hindrance was avoided by previous sample dilution in $n$-hexane jointly with a slower stirring (a mixing table instead of a vortex). It 
was experimentally evaluated that the best conditions were attained when the vegetable oil was diluted 1:1 (v/v) in $n$-hexane. The procedure was carried out with $1.2 \mathrm{~mL}$ of sample to partially compensate the decrease in the amount of unsaturated compounds because of the dilution. As observed for biodiesel samples, better analytical response was also achieved with $5 \mathrm{~min}$ of stirring (Figure 2).

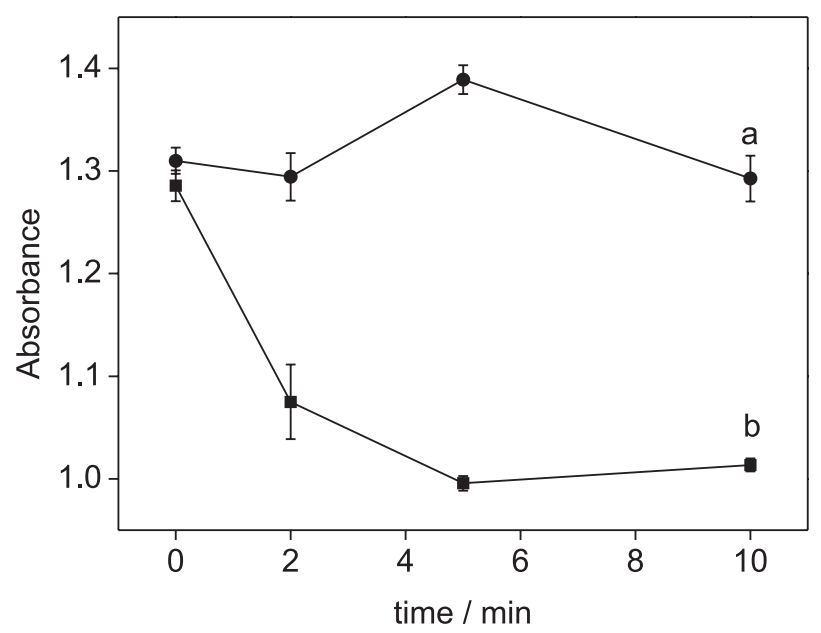

Figure 2. Effect of the time for halogenation reaction on the reference (a) and analytical (b) signals. The experiment was carried out with a 1-fold diluted soybean oil sample. Values refer to mean values of triplicate measurements.

\section{Analytical features}

Under optimized conditions, linear responses were obtained from 10 to $106 \mathrm{~g}$ and 20 to $144 \mathrm{~g} \mathrm{I}_{2}$ per $100 \mathrm{~g}$, described by equations $\mathrm{A}=0.03169+0.00515 \mathrm{C}(\mathrm{r}=0.998)$ and $\mathrm{A}=0.06494+0.00238 \mathrm{C}(\mathrm{r}=0.999)$ for biodiesel and vegetable oil samples, respectively, where $\mathrm{A}$ is the absorbance and $\mathrm{C}$ is the iodine value in $\mathrm{g}_{2}$ per $100 \mathrm{~g}$. For biodiesel samples, the coefficient of variation $(\mathrm{CV})$ and the limit of detection (LOD) were estimated at 5.0\% ( $\mathrm{n}=8)$ and $2.5 \mathrm{~g} \mathrm{I}_{2}$ per $100 \mathrm{~g}$, respectively, while the corresponding values for vegetable oil samples were 3.0\% $(\mathrm{n}=10)$ and $7 \mathrm{~g} \mathrm{I}_{2}$ per $100 \mathrm{~g}$. The procedure consumed only $1.0-1.2 \mathrm{~mL}$ of sample, $365 \mu \mathrm{g}$ of $\mathrm{I}_{2}$ and $42 \mathrm{mg}$ of KI and generated ca. $2.4 \mathrm{~mL}$ of waste per determination.

In order to evaluate the occurrence of matrix effects, samples of different sources (tallow, soybean and cotton oil) with the same iodine value according to the reference method were analyzed by the proposed procedure. The analytical signal obtained by using biodiesel produced from $90 \%$ soybean oil and $10 \%$ tallow $(0.467 \pm 0.007)$ was $15 \%$ lower than those obtained with biodiesel produced from $90 \%$ soybean and $10 \%$ cotton oils $(0.540 \pm 0.009)$ and soybean only $(0.540 \pm 0.010)$. Differences of up to $70 \%$ were observed for samples of refined and degummed corn oils. This indicates the occurrence of matrix effects and that analytical curves obtained with biodiesel derived exclusively from vegetable oils could not be used for the quantification of iodine value in samples from animal fat, as well as analytical curves obtained with refined oils (soybean, corn or canola) cannot be used to quantify iodine value in degummed oils. Similar effects were observed in a batch procedure for the determination of glycerol in biodiesel. ${ }^{15}$ In the proposed procedure, the matrix effects seem to be related to the different solubility of $\mathrm{I}_{2}$ in the samples from different sources. The drawback was overcome by matrix matching, i.e., by using a biodiesel from soybean oil as reference for analysis of biodiesel from vegetable sources, refined soybean oil for analysis of refined oils and degummed soybean oil for analysis of degummed oils. In relation to biodiesel analysis, matrix matching is feasible because it is obligatory to the producers to inform the feedstocks and their respective proportions used in production of biodiesel (e.g. article 5 of ANP, resolution No. 45 of 08/25/2014). ${ }^{18}$

Biodiesel and vegetable oil samples were analyzed by the proposed and the reference procedures based on iodometric titrations ${ }^{11,14}$ (Tables 1 and 2). The variances were compared by the $F$-test and values for all the analyzed

Table 1. Iodine value in biodiesel samples determined by the proposed and reference procedures

\begin{tabular}{lccc}
\hline \multirow{2}{*}{ Sample } & \multicolumn{1}{c}{ Iodine value / $\left(\mathrm{g} \mathrm{I}_{2}\right.$ per $100 \mathrm{~g}$ of sample $)$} & F-value \\
\cline { 2 - 3 } $100 \%$ soybean 1 & Proposed & Reference $^{\mathrm{a}}$ & 4.0 \\
$100 \%$ soybean 2 & $109 \pm 1$ & $106 \pm 2$ & 1.0 \\
$90 \%$ soybean/10\% cotton & $108 \pm 1$ & $103 \pm 1$ & 1.0 \\
$90 \%$ soybean/10\% tallow 1 & $124 \pm 1$ & $104 \pm 1$ & 1.0 \\
$90 \%$ soybean/10\% tallow 2 & $106 \pm 2$ & $106 \pm 2$ & 9.0 \\
$90 \%$ soybean/10\% tallow 3 & $108 \pm 2$ & $98 \pm 6$ & 1.0 \\
\hline
\end{tabular}

${ }^{\mathrm{a}} F_{\text {critical }}=19.0$ (95\% confidence level). 
Table 2. Iodine value in refined and degummed oil samples determined by the proposed and reference procedures

\begin{tabular}{lccc}
\hline \multirow{2}{*}{ Sample } & Iodine value / $\left(\mathrm{g} \mathrm{I}_{2}\right.$ per $100 \mathrm{~g}$ of sample $)$ & \multirow{2}{*}{ F-value } \\
\cline { 2 - 3 } & Proposed & Reference $^{\mathrm{a}}$ & 1.0 \\
\hline Refined soy & $133 \pm 1$ & $143 \pm 1$ & 1.8 \\
Refined corn & $117 \pm 3$ & $116 \pm 4$ & 9.0 \\
Refined canola 1 & $118 \pm 6$ & $112 \pm 2$ & 4.0 \\
Refined canola 2 & $106 \pm 4$ & $110 \pm 2$ & 6.2 \\
Degummed soy 1 & $133 \pm 5$ & $130 \pm 2$ & 4.0 \\
Degummed soy 2 & $123 \pm 6$ & $123 \pm 3$ & \\
\hline
\end{tabular}

${ }^{\mathrm{a}} F_{\text {critical }}=19.0$ (95\% confidence level).

samples (see Tables 1 and 2) were lower than the critical value for two degrees of freedom (19.0), thus indicating that the variances are not significantly different at the $95 \%$ confidence level. For accuracy assessment, the mean values were compared by a paired $t$-test and the obtained values ( 1.736 for biodiesel and 0.289 for vegetable oils) were also lower than the critical one (2.571), thus indicating that the results agreed at the $95 \%$ confidence level.

Advantages of the proposed procedure were evidenced when the analytical characteristics were compared to those achieved in the official methods (Table 3). These methods require more toxic organic solvents (carbon tetrachloride or cyclohexane were herein replaced by $n$-hexane) and the solvent consumption is 30 -fold higher than in the proposed procedure; moreover, the Wijs reagent was replaced by an aqueous dilute triiodide solution. Moreover, it consumes about $25^{11}$ to 30 -fold ${ }^{19}$ less organic solvent in comparison to other alternative procedures cited in the literature. The coefficient of variation is comparable to the attained in the official procedure ${ }^{9}$ for determination of iodine value in biodiesel. The analysis time was 15 -fold lower than in the official method ${ }^{9}$ and 6-fold lower than in other procedures. ${ }^{11,19}$ The proposed procedure is then fast, practical, and requires only simple equipment and materials such as vortex, centrifuge, and spectrophotometer to perform the analysis. Sample preparation involved only dilution in hexane, and all the processes were carried out in the same vessel, which minimizes risks of contamination and loss of the analyte. These characteristics make the procedure attractive for analysis of biodiesel and vegetable oils directly at the production plants, also because of the environmental friendliness. ${ }^{20}$

A quantitative spot test based on digital images was recently proposed for determination of iodine value in biodiesel with negligible reagent consumption and waste generation. ${ }^{13}$ Although a good analytical performance was attained, the proposal described herein has advantages in relation to detection limit (ca. 3-fold lower) and ruggedness. The latter is mainly related to the effects of evaporation of organic solvents (i.e., ethanol and hexane) in the spot test, which involves solution volumes in the order of microliters. This reflected directly in the precision observed in sample

Table 3. Main characteristics of the procedures for the determination of iodine value in vegetable oil and biodiesel

\begin{tabular}{|c|c|c|c|c|c|}
\hline Procedure & $\mathrm{CV} / \%$ & Sample mass / g & $\begin{array}{l}\text { Solvent consumption } \\
\qquad / \mathrm{mL}\end{array}$ & Analysis time / min & Reference \\
\hline \multicolumn{6}{|c|}{ Oil } \\
\hline Volumetry-visual end point detection & - & 0.400 & 15 (cyclohexane) & 30 & 10 \\
\hline Volumetry-visual end point detection & - & $0.10-0.15$ & 20 (ethanol) & 30 & 11 \\
\hline EN 14111 (Wijs) & 3.0 & $0.13-0.15$ & 20 (cyclohexane) & 75 & 9 \\
\hline Proposed procedure & 3.0 & 0.550 & 0.6 (hexane) & 5 & this work \\
\hline \multicolumn{6}{|c|}{ Biodiesel } \\
\hline EN 14111 (Wijs) & 3.0 & $0.13-0.15$ & 20 (cyclohexane) & 75 & 9 \\
\hline Spot test-digital images & 4.9 & 0.035 & 0.020 (hexane) & 7 & 13 \\
\hline Potentiometry & 1.5 & $0.13-0.15$ & 15 (ethanol) & 30 & 19 \\
\hline Proposed procedure & 5.0 & $0.820-0.880$ & 0.5 (hexane) & 7 & this work \\
\hline
\end{tabular}

$\mathrm{CV}$ : coefficient of variation. 
analysis, with $\mathrm{CV}$ of up to $8.4 \%$ estimated in the spot test. ${ }^{13}$ In addition, the proposed procedure is applicable also to vegetable oils, which is useful for quality control during biodiesel production.

\section{Conclusions}

The present proposal is feasible for analysis of both biodiesel and vegetable oils and requires only inexpensive and widely available equipment. Moreover, it minimizes the consumption of samples, reagents, and solvents, thus also the waste volumes, meeting the requirements of green analytical chemistry. Calibration was successfully carried out by matrix matching, which overcame the matrix effects expected for such complex samples. The results obtained agreed with the reference methods used for biodiesel and vegetable oil analysis, then being a practical alternative to the official methods.

\section{Acknowledgments}

The authors thank the fellowships and financial support from the Brazilian agencies São Paulo Research Foundation (FAPESP, 2016/00138-0), National Council of Technological and Scientific Development (CNPq), and Coordination for the Improvement of Higher Education Personnel (CAPES). This work is a contribution of the National Institute of Advanced Analytical Sciences and Technology (INCTAA).

\section{References}

1. Technical Committee of the Institute of Shortening and Edible Oils; Food Fats and Oils, Part 10; Institute of Shortening and Edible Oils, Inc.: Washington, DC, USA, 2016.

2. Xia, W.; Budge, S. M.; Eur. J. Lipid Sci. Technol. 2018, 120, 2.

3. Dias, L. A. S.; CBAB, Crop Breed. Appl. Biotechnol. 2011, 1, 11.

4. Wright, H. J.; Segur, J. B.; Clark, H. V.; Coburn, S. K.; Langdon, E. E.; Dupuis, R. N.; Oil Soap 1944, 21, 145.
5. World Energy Council; Biofuels: Policies, Standards and Technologies; World Energy Council: London, UK, 2010. Available at https://www.worldenergy.org/wp-content/ uploads/2012/10/PUB_Biofuels_Policies_Standards_and_ Technologies_2010_WEC.pdf, accessed in March 2018.

6. Muniz, M. A. P.; Santos, M. N. F.; Costa, C. E. F.; Morais, L.; Lamarão, M. L. N.; Costa, R. M. R.; Silva, J. O. C.; Pharmacogn. Mag. 2015, 11, 147.

7. Mittelbach, M.; Bioresour. Technol. 1996, 56, 1.

8. Freire, L. M. S.; Filho, J. R. C.; Moura, C. V. R.; Soledade, L. E. B.; Stragevitch, L.; Cordeiro, A. M. T. M.; Santos, I. M. G.; Souza, A. G.; Fuel 2012, 95, 1.

9. EN 14111, Fat and Oil Derivatives - Fatty Acid Methyl Esters (FAME) - Determination of Iodine Value - Volumetric Titration; European Committee for Standardization, Brussels, 2003.

10. Siew, W. L.; Tang, T. S.; Tan, Y. A.; PORIM: Test Methods; Palm Oil Research Institute of Malaysia: Kuala Lumpur, 1995.

11. Shimamoto, G. G.; Aricetti, J. A.; Tubino, M.; Food Anal. Methods 2016, 9, 10.

12. Pereira, A. C.; Rocha, F. R. P.; Anal. Chim. Acta 2014, 829, 28.

13. Soares, S.; Lima, M. J. A.; Rocha, F. R. P.; Microchem. J. 2017, $133,195$.

14. Aricetti, J. A.; Maciel, A. J. S.; Lopes, O. C.; Tubino, M.; J. ASTM Int. 2010, 7, 1 .

15. Ribeiro, M. S.; Rocha, F. R. P.; Microchem. J. 2013, 106, 23.

16. Sato, R. T.; Stroppa, P. H. F.; Silva, A. D.; Oliveira, M. A. L.; Quim. Nova 2016, 39, 3.

17. Canakci, M.; Gerpen, J. V.; Am. Soc. Agric. Eng. 2003, 44, 6.

18. Agência Nacional do Petróleo, Gás Natural e Biocombustíveis (ANP); Resolução No. 45 de 25/08/2014 Dispõe sobre a Especificação do Biodiesel Contida no Regulamento Técnico ANP No. 3 de 2014 e as Obrigações quanto ao Controle da Qualidade a Serem Atendidas pelos Diversos Agentes Econômicos que Comercializam o Produto em Todo o Território Nacional; DOU 26/08/2014, Brasília, 2014.

19. Tubino, M.; Aricetti, J. A.; Fuel 2013, 103, 1158.

20. Amais, R. S.; Teixeira, L. S. G.; Rocha, F. R. P.; Anal. Methods 2015, 7, 4396.

Submitted: December 4, 2017

Published online: March 9, 2018 